\title{
The Strain-Rate Dependence of the Ductile-Brittle Transition Temperature of Aluminium in Liquid Metals
}

\author{
By Hiroyuki Ichinose and Chiaki Oouchi*
}

\begin{abstract}
The ductile-brittle transition temperature of aluminium in the presence of $\mathrm{Hg}-3 \% \mathrm{Zn}$ or $\mathrm{Sn}-10 \% \mathrm{Zn}$ liquid was investigated as a function of strain rate. In both liquids, the transition temperature was higher as the strain rate increased. The change of the transition temperature in $\mathrm{Hg}-3 \% \mathrm{Zn}$ was $53^{\circ} \mathrm{C}$ in the strain rate range used in the investigation, but that in $\mathrm{Sn}-10 \% \mathrm{Zn}$ was only $10^{\circ} \mathrm{C}$. The results were discussed on the basis of stress concentrations for crack nucleation and yielding at the tip of the piled-up dislocations. However, the discrepancy between prediction and experiment was obtained in the case of $\mathrm{Hg}-3 \% \mathrm{Zn}$, and this can be understood in terms of the "stress for definite plastic flow" -introduced previously.

(Received March 31, 1967)
\end{abstract}

\section{Introduction}

The ductile-brittle transition of face-centred cubic metals in a suitable liquid metal environment is one of the most attractive problems in this field. There has been some observation on the strain-rate dependence of the transition temperature and the result is expressed empirically in the following manner :

$$
T_{c} \propto \ln \dot{\varepsilon}^{(1)} \text {. }
$$

Recently aluminium has been known to exhibit the transition in the presence of $\mathrm{Hg}-3 \% \mathrm{Zn}$ or $\mathrm{Sn}-10 \% \mathrm{Zn}$ liquid, and the dependence of transition temperature on the grain size was quite interesting ; in $\mathrm{Hg}-3 \% \mathrm{Zn}$ the transition temperature was higher as the grain size became smaller, and in $\mathrm{Sn}-10 \% \mathrm{Zn}$ the tendency was reversed ${ }^{(2)}$.

Accordingly, it is desirable for a better understanding of this phenomenon to examine and establish the relationship between the transition temperature of aluminium in the above two liquids and the strain rate.

* Department of Metallurgical Engineering, Yokohama National University, Yokohama, Japan.

(1) W. Rostoker, J. M. McCaughey and H. Markus : Embrittlement by Liquid Metals, Reinhold (1960).

(2) H. Ichinose: Trans. JIM, 9 (1968), 35.

\section{Materials and Procedures}

The materials and procedures are described in a previous paper ${ }^{(2)}$. Ordinary tensile specimens (gauge section : $20 \mathrm{~mm}$ in length and $10 \mathrm{~mm}$ in breadth) were obtained from a $3 \mathrm{~mm}$ thick sheet of aluminium $(99.99$ $\%$ ) which had been cold rolled by $88 \%$.

The specimens were annealed in vacuum and then slowly furnace-cooled to avoid thermal stress. After chemical polishing, the gauge section was wetted with either of $\mathrm{Hg}-3 \% \mathrm{Zn}$ or $\mathrm{Sn}-10 \% \mathrm{Zn}$.

After setting the specimen in the Olsen-type tensile machine at a desired temperature, the testing was carried out at a cross-head speed of 3 or $0.7 \mathrm{~mm} / \mathrm{min}$, corresponding to the strain rate of $1.8 \times 10^{-3}$ or $4.2 \times$ $10^{-4} \mathrm{sec}^{-1}$, respectively.

The data at a cross-head speed of $21 \mathrm{~mm} / \mathrm{min}(1.2 \times$ $\left.10^{-2} \mathrm{sec}^{-1}\right)$ can be obtained from Reference ${ }^{(2)}$.

\section{Experimental Results}

Fig. 1 shows the fracture stress and the elongation of the specimen with a grain size of $0.20 \mathrm{~mm}$ in $\mathrm{Hg}_{-}$ $3 \% \mathrm{Zn}$ as a function of temperature. The fracture stress was obtained by $\frac{F}{A}(1+\varepsilon)$, where $F$ is the load and 
$A$ is the original cross-sectional area of the specimen'; $\varepsilon$ is the overall elongation, which includes elongations due to crack nucleation, propagation, and positive error in the measurement (since the value was measured by restoring the broken pieces to the original form of the specimen).
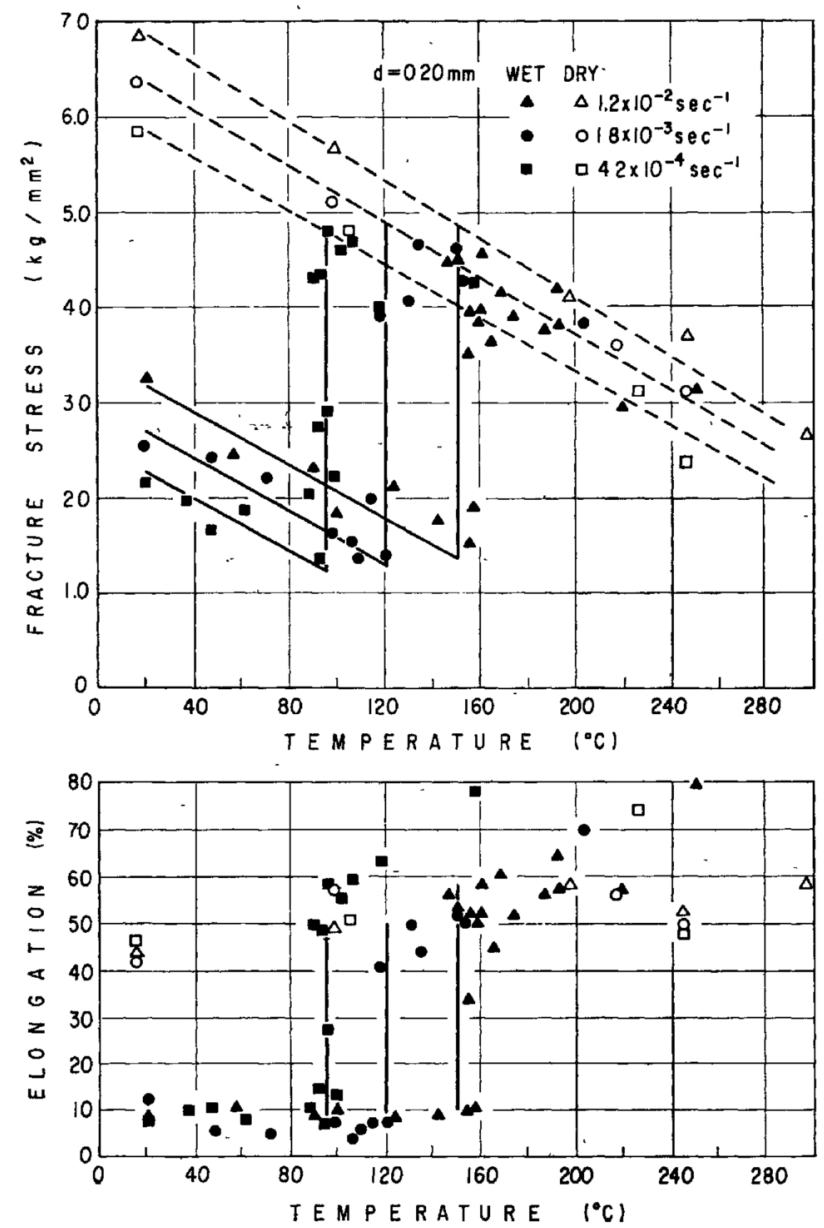

Fig. 1 Fracture stress and elongation of the specimen of aluminium with a grain size of $0.20 \mathrm{~mm}$ in $\mathrm{Hg}-3 \% \mathrm{Zn}$ as a function of temperature, at three strain rates.

A sharp transition is observed in both the elongation curves and the fracture stress curves. The transition temperature is higher as the strain rate increases, and the amount of change in transition temperature is $55^{\circ} \mathrm{C}$ in the strain rate range used in the present experiment. In the ductile region, the wetted fracture stresses lie on the fracture stress curves of the dry specimens. The same tendency holds for the elongation curves, though the scattering is fairly large. As shown in Fig. 1, the brittle fracture stress curves can be approximated by the straight lines parallel to each other.

The same result was obtained on the specimens with grain sizes of 2.3 and $0.043 \mathrm{~mm}$, respectively. The relation between the brittle fracture stress and the strain rate at $20^{\circ} \mathrm{C}$ was obtained from the straight Hithes in Fig. 1 and is shown in Fig. 2. The brittle fracture stress is proportional to the logarithm of strain rate, and the slopes of the straight lines for different grain sizes are almost the same. In a previous report (2), the brittle fracture stress was expressed as a function of temperature and grain size. Accordingly, the brittle fracture stress can be expressed as a function of temperature, grain size and strain rate as in the following :

$$
\sigma_{f} \sim-C T+D \log \dot{\varepsilon}+K d^{-\frac{1}{2}},
$$

where $C$ and $D$ are constants, $K=\sqrt{\frac{6 \pi G \gamma}{1-\nu}}(3)$ and

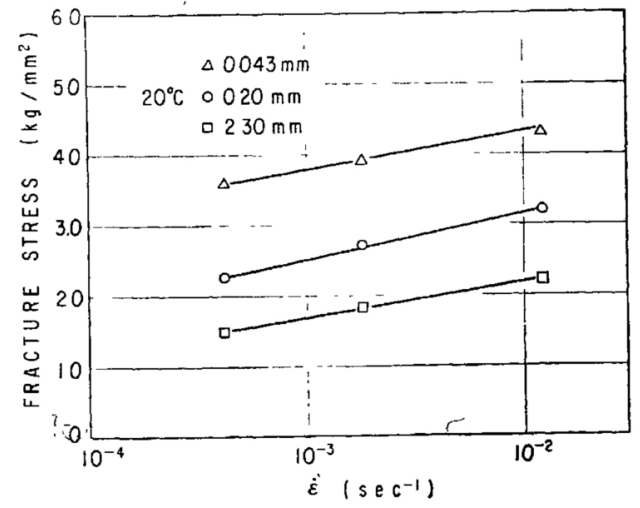

Fig. 2 Relation between the brittle fracture stress and strain rate on the specimen in $\mathrm{Hg}-3 \% \mathrm{Zn}$, at $20^{\circ} \mathrm{C}$.
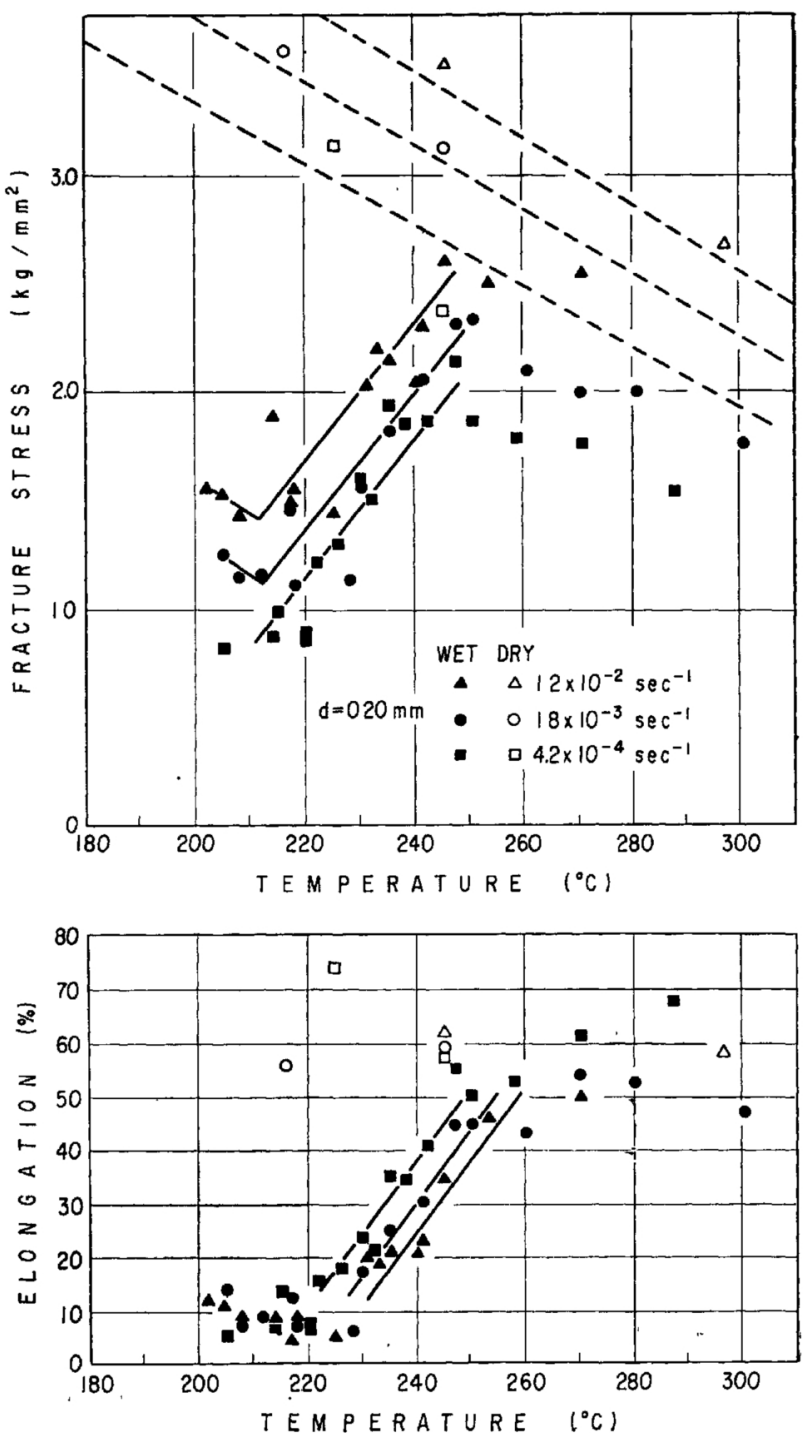

Fig. 3 Fracture stress and elongation of the specimen of aluminium with grain size of $0.20 \mathrm{~mm}$ in $\mathrm{Sn}-10 \% \mathrm{Zn}$ as a function of temperature, at three strain rates.

(3) A. N. Stroh: Adv. Phys., 6 (1957), 418 
is independent of temperature, and $\gamma$ is the interfacial energy in a liquid envirifonment ${ }^{(1)(4)}$.

The results for the grain size of $0.20 \mathrm{~mm}$ in $\mathrm{Sn}-10$ $\% \mathrm{Zn}$ are shown in Fig. 3. The same observation was obtained for the grain sizes of 2.3 and $0.043 \mathrm{~mm}$, respectively. The transition is rather gradual compared to the case of $\mathrm{Hg}-3 \% \mathrm{Zn}$. In the ductile region, the wetted fracture stress and elongation lie a little below the fracture stress and elongation curves for the dry specimens. This may be due to the slight grainboundary penetration that occurred at high temperatures. The transition temperature can be read at $30 \%$ elongation (which is the average of the brittle fracture and the ductile fracture elongations near the transition). The transition temperature is higher with increasing strain rate, as in the case of $\mathrm{Hg}-3 \% \mathrm{Zn}$. However, the important point is that the amount of change in transition temperature in the same strain rate range is only $10^{\circ} \mathrm{C}$.

\section{Discussion}

If the transition is described by the competition of crack nucleation and yielding at the tip of piled-up dislocations at grain boundary, the condition for the transition is expressed by the following relation ${ }^{(2)}$, using the crack nucleation equation by $\operatorname{Stroh}^{(3)}$ and the yielding equation by Eshelby et al. ${ }^{(5)}$ :

$$
\frac{6 \pi G_{\gamma}}{(1-\nu) d}=\left(\sigma_{y}-\sigma_{0},{ }_{T}\right) \sigma_{y}
$$

where $\sigma_{y}$ is the tensile yield stress and $\sigma_{0}, T$ is the frictional stress at $T^{\circ} \mathrm{C}$. This is an equation of the same form as derived by Cottrell(6) and Petch(7).

As to the strain-rate dependence of yield stress, there are two ways of approximation; one depends on the straight-line relation in the logarithm-logarithm scale (8) and the other on that in the semi-logarithm scale ${ }^{(9)}$. If the strain rate range is not too large, the approximation by the semi-logarithm scale gives a good result. As for the temperature and grain size, the yield stress was approximated in a form, $-A T+K_{y} d^{-\frac{1}{2}(2)}$. Then,

$$
\sigma_{y}=\sigma_{0,1}-A T+B \log \dot{\varepsilon}+K_{y} d^{-\frac{1}{2}},
$$

where $\sigma_{0,1}$ is the frictional stress at $0^{\circ} \mathrm{C}$ and at a unit strain rate.

Substituting this into Eq. (2), we obtain

$$
\frac{6 \pi G \gamma}{(1-\nu) d}=K_{y} d^{-\frac{1}{2}}\left\{\sigma_{0,1}-A T_{c}+B \log \dot{\varepsilon}+K_{y} d^{-\frac{1}{2}}\right\} \text {. }
$$

The treatment is based on the approximation that the increase in strain rate results in the change in frictional stress. Rearranging the parameters in the above equation, we obtain

(4) H. Nichols and W. Rostoker: Acta Met., 8 (1960), 788

(5) J. D. Eshelby, F.:C. Frank and F. R. N. Nabarro: Phil. Mag., 42 (1951), 351.

(6) A. H. Cottrell: Trans. AIME, 212 (1958), 192.

(7) N. J. Petch: Fracture, ed. by Averbach. Felbeck, Hahn and Thomas, M. I. T. Technology Press, p. 54 (1959).

( 8 ) e.g., J. W. Pugh: Trans. ASM, 47 (1955), 984.

(9) e.g., S. Sakui, T. Nakamura and M.Ohmori: J. of Iron and Steel Inst. of Japan, 49 (1963), 996.

$$
A T_{c}=\sigma_{0,1}+B \log \dot{\varepsilon}+\left\{K_{y}-\frac{6 \pi G \gamma}{(1-\nu) K_{y}}\right\} d^{-\frac{1}{2}}
$$

Thus the dependence of transition temperature on the strain rate or grain size is expressed as (with $\left.\sqrt{\frac{6 \pi G \gamma}{1-\nu}}=K^{(3)}\right)$ :

$$
\begin{aligned}
& \frac{d T_{c}}{d \log \dot{\varepsilon}}=\frac{B}{A} \\
& \frac{d T_{c}}{d d^{-\frac{1}{2}}}=\frac{1}{A}\left\{K_{y}-\frac{K^{2}}{K_{y}}\right\}
\end{aligned}
$$

There have been some reasonable proposals of the function of liquid metals, such as the decrease in surface energy of the solid (1)(4) and the bond strength of the stressed solid(10) (15). However, these have not been well established at present. At any rate, it is a sound idea that the brittle fracture occurs at a critical stress concentration, in view of the condition for crack nucleation $^{(3)}$ (the dominant stage of brittle fracture is nucleation $^{(3)(16)}$ ).

Then, it is a problem whether the critical fracture stress concentration necessary for crack nucleation is satisfied at grain boundary during deformation or not (since intergranular brittle fracture occurs at low temperatures). The stress concentration at grain boundary during deformation is largely temperature-dependent ; i.e., it decreases with increasing temperature. Contrary to this, the critical fracture stress concentration is almost independent of temperature. At low temperature, the concentration is sufficient for crack nucleation and leads to brittle fracture, whereas at high temperatures it is not sufficient, resulting in ductile fracture. Thus, the ductile-brittle transition is observed.

If the stress concentration at grain boundary remains constant in a large portion of plastic flow after yielding, the yield stress can be a measure of ductility, and the above analysis holds true as explained in the previous report ${ }^{(2)}$. However, if the stress concentration at grain boundary increases af ter passing the yield point, there is still the possibility of embrittlement by liquid metals. In such a case, the yield stress cannot be a measure of ductility, and the "stress for definite plastic flow $\sigma_{p} "(2)$ should be used for the transition. Thus, Eqs. (5) and (6) are written as follows :

$$
\frac{d T_{c}}{d \log \dot{\varepsilon}}=\frac{B^{\prime}}{A^{\prime}}
$$

and

$$
\frac{d T_{c}}{d d^{-1-}}=\frac{1}{A^{\prime}}\left\{K_{p}-\frac{K^{2}}{K_{p}}\right\},
$$

(10) N. S. Stoloff and T. L. Johnston: Acta Met., 11 (1963), 251.

(11) A. R. C. Westwood and M.H. Kamdar: Phil. Mag., 8 (1963), 787.

(12) E. Levine, H. Solomon and I. Cadoff: Acta Met., 12 (1964), 1119.

(13) E. Levine and I. B. Cadoff : Trans. AIME, 230 (1964), 1116.

(14) A R. C. Westwood, D. L. Goldheim and E. N.Pugh : Acta Met., $13(1965), 695$.

(15) H. Nichols and W. Rostoker : Trans. AIME, 224 (1962), 1258.

(16) E. Smith : Acta Met., 14 (1966), 985, 991. 
where $A^{\prime}, B^{\prime}$ and $K_{p}$ are the temperature-, strain rateand grain size- dependence of stress for the definite plastic flow, respectively.

From the above argument, the experimental results are discussed as follows.

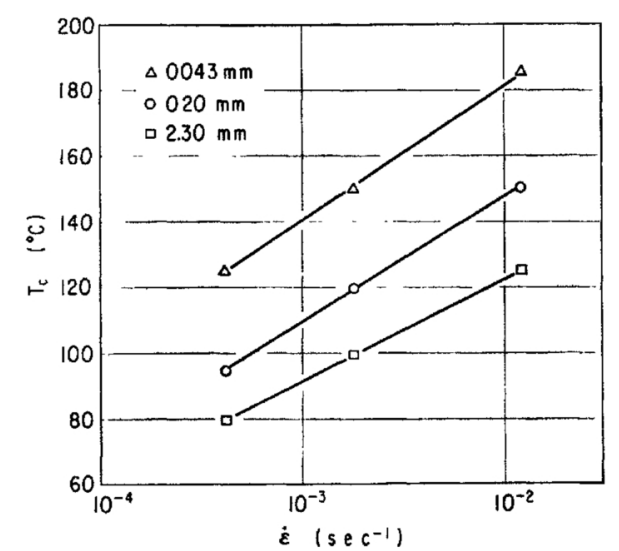

Fig. 4 Transition temperature of the specimen in $\mathrm{Hg}-3 \% \mathrm{Zn}$ as a function of strain rate, for three grain sizes.

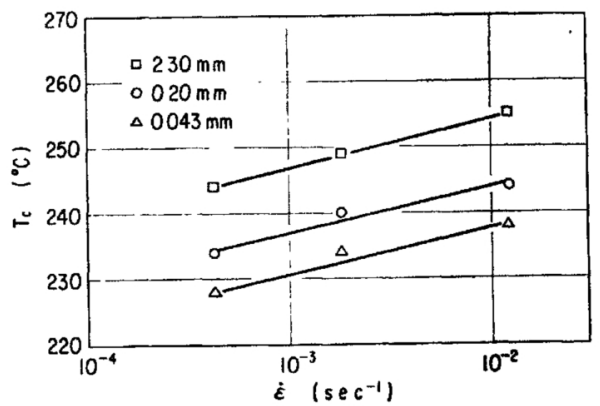

Fig. 5 Transition temperature of the specimen in $\mathrm{Sn}-10 \% \mathrm{Zn}$ as a function of strain rate, for three grain sizes.

The dependence of transition temperature on the strain rate is plotted in Figs. 4 and 5 in the semilogarithm scale. Fig. 4 is the results for three grain sizes in $\mathrm{Hg}-3 \% \mathrm{Zn}$. The strain rate dependence of transition temperature is a little higher, as the grain size becomes smaller. The average change in transition temperature is $53^{\circ} \mathrm{C}$ in the strain rate range used. On the other hand, Fig. 5 shows the results in $\mathrm{Sn}-10$ $\% \mathrm{Zn}$. The strain-rate dependence of transition temperature is almost the same for the three different grain sizes, and the average change in transition temperature is only $10^{\circ} \mathrm{C}$ in the same strain rate range.

Before applying Eq. (5) or $(5)^{\prime}$, it is important to find out the relation between $\sigma_{y}$ and $\sigma_{p}$. In Fig. 6 the stress range from the proportional limit up to $5 \%$ flow stress (on the specimen with a grain size of $0.20 \mathrm{~mm}$ ) is plotted against temperature for the three strain rates. The lower mark represents the proportional limit and the upper mark, $5 \%$ flow stress. The dotted lines show the brittle fracture stress as obtained from Fig. 1. Though the yield stress in the annealed specimen of aluminium is difficult to be defined, it may be taken as the stress at the proportional limit. As is evident from Fig. 6, brittle fracture occurred with some plastic flow. In this case, the critical fracture stress concentration is satisfied after some plastic flow, i.e., the stress concentration during deformation increases after passing the yield point. Hence, the yield

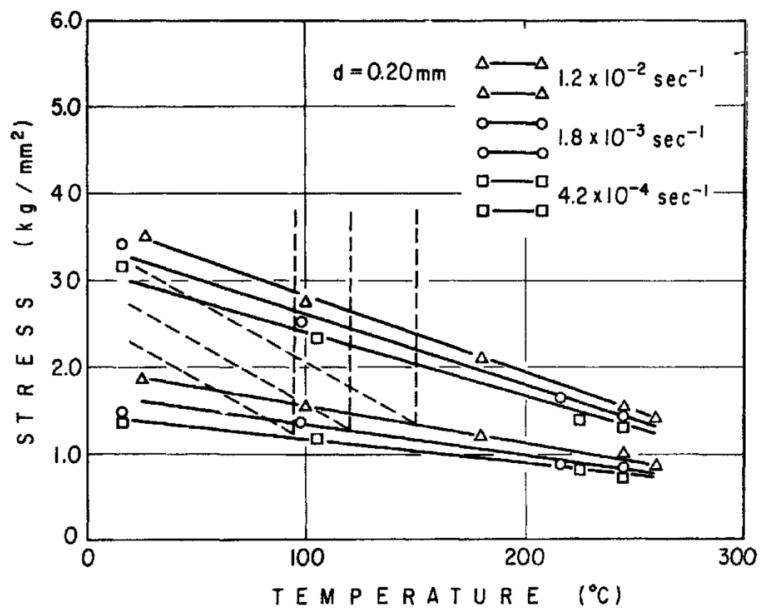

Fig. 6 The stress range from the proportional limit to $5 \%$ flow stress on the specimen with a grain size of $0.20 \mathrm{~mm}$ as a function of temperature, at three strain rates, with brittle fracture stress in $\mathrm{Hg}-3 \% \mathrm{Zn}$ (dotted lines).

stress is of no importance in the transition, and the stress for definite plastic flow should be used. Thus, Eq. (5)' is applied for analysis.

The slopes of the $\mathrm{Tc}$ - $\log \dot{\varepsilon}$ curves for $\mathrm{Hg}-3 \% \mathrm{Zn}$ and $\mathrm{Sn}-10 \% \mathrm{Zn}$ are obtained from Figs. 4 and 5, respectively. The values of $A^{\prime}$, i.e., the temperature dependence of $\sigma_{p}$ are approximated by those for the brittle fracture stress (The exact position of $-\sigma_{p}$ against temperature is unknown, but $\sigma_{p}$ is larger than the fracture stress in the brittle region and both are equal at the transition). These values are shown in Table 1, the values of $B^{\prime}$ being calculated from Eq. $(5)^{\prime}$.

Table 1

\begin{tabular}{c|c|c|c|c}
\hline & $\begin{array}{c}\text { grain size } \\
(\mathrm{mm})\end{array}$ & $\begin{array}{c}\frac{d T_{c}}{d \log \dot{\varepsilon}} \\
\left({ }^{\circ} \mathrm{C}\right)\end{array}$ & $\begin{array}{c}A^{\prime} \\
\left(\mathrm{kg} / \mathrm{mm}^{2} \mathrm{deg} .\right.\end{array}$ & $\begin{array}{c}B^{\prime} \\
\left(\mathrm{kg} / \mathrm{mm}^{2}\right)\end{array}$ \\
\hline \multirow{3}{*}{$\mathrm{Hg}$} & 0.043 & 40 & & 0.56 \\
& 0.20 & 38 & $1.39 \times 10^{-2}$ & 0.53 \\
& 2.3 & 31 & & 0.43 \\
\hline \multirow{3}{*}{$\mathrm{Sn}$} & 0.043 & 7.0 & & 0.12 \\
& 0.20 & 7.0 & $1.76 \times 10^{-2}$ & 0.12 \\
\hline
\end{tabular}

Fig. 7 shows the relation between the stress range (from the proportional limit up to $5 \%$ flow stress) and the strain rate for the three grain sizes. The temperature indicated is the average transition took place for a particular grain size. The values of $B^{\prime}$ are located at arbitrary positions.

As shown in Fig. 7, the value of $B^{\prime}$ is much larger than $B$, i.e., the strain-rate dependence of yield stress (the proportional limit) in each case. The reason for this can be understood from the same sort of consideration presented in the previous paper ${ }^{(2)}$. As found experimentally in the brittle region (Fig. 6), the 
fracture stress crosses over the stress range in such a way that it is in the immediate vicinity of the proportional limit at the transition and is close to $5 \%$ flow stress at $0^{\circ} \mathrm{C}$. In other words, with decreasing temperature, the fracture stress is equal to the flow

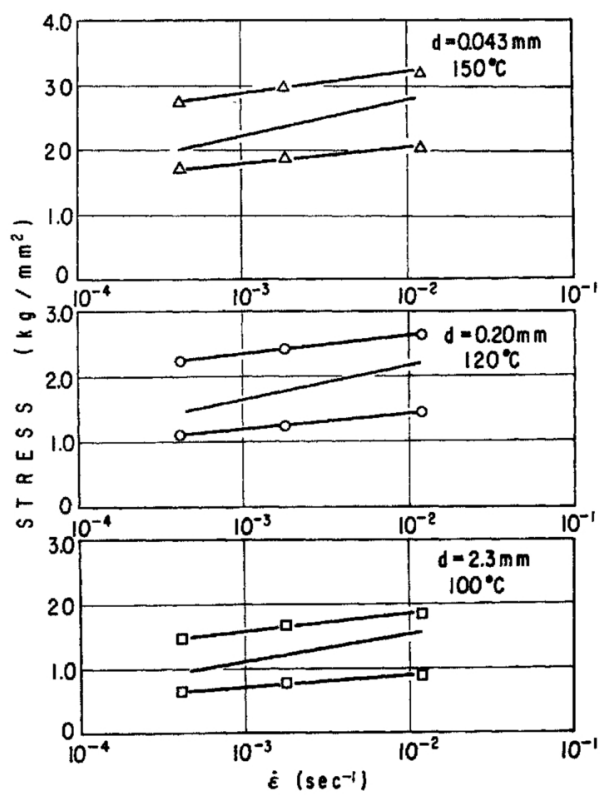

Fig. 7 Relation between the stress range (from the proportional limit to $5 \%$ flow stress) and strain rate, with the expected value of $B^{\prime}$ (in $\mathrm{Hg}-3 \% \mathrm{Zn}$ ), for three grain sizes.

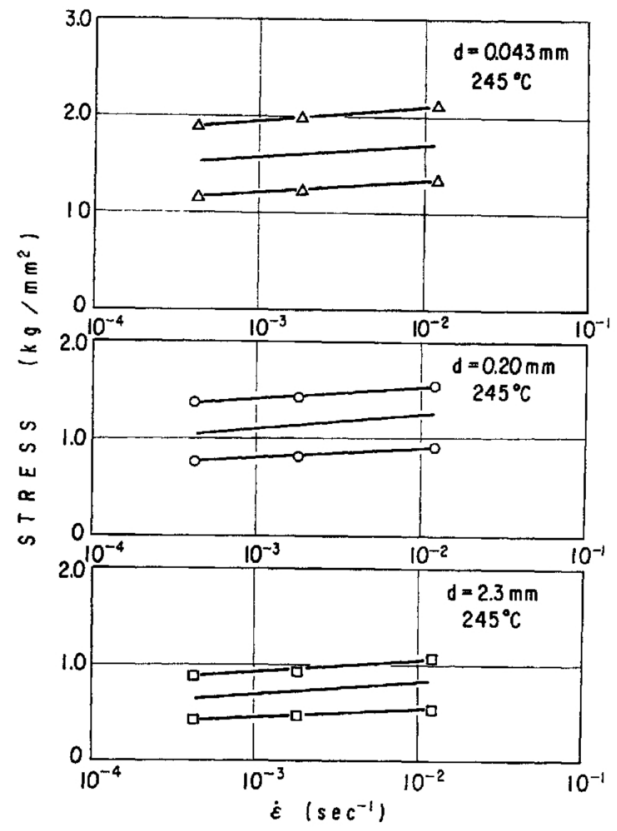

Fig. 8 Relation between the stress range (from the proportional limit to $5 \%$ flow stress) and strain rate, with the expected value of $\boldsymbol{B}^{\prime}$ (in $\mathrm{Sn}-10 \% \mathrm{Zn}$ ), for three grain sizes.

stress corresponding to the increased elongation. At the transition $\sigma_{p}=\sigma_{f}$, and $\sigma_{p}>\sigma_{f}$ in the brittle region. Therefore, $\sigma_{p}$ is also equal to the flow stress corresponding to the elongation increased with decreasing temperature. Now let us review the dependence of $\sigma_{p}$ on the strain rate at a certain temperature, for example, $95^{\circ} \mathrm{C}$ (Fig. 6). For the smallest strain rate, $\sigma_{p}\left(=\sigma_{f}\right)$, is very close to the proportional limit. But, with increasing strain rate, $\sigma_{p}$ is equal to the flow stress corresponding to the increased elongation. Thus, the value of $B^{\prime}$ is much larger than that of $B$.

Fig. 8 shows the results in $\mathrm{Sn}-10 \% \mathrm{Zn}$. In this case, the coincidence of $B^{\prime}$ and $B$ is observed because of the small temperature range in which the transition took place.

Thus, the observation that the strain-rate dependence of transition temperature in $\mathrm{Hg}-3 \% \mathrm{Zn}$ is much larger than that in $\mathrm{Sn}-10 \% \mathrm{Zn}$ is mainly due to the strain-rate dependence of $\sigma_{p}$ at each temperature where the transition took place.

Thus, the experimental results are qualitatively explained by the introduction of the stress for definite plastic flow. It is desirable an experiment in which this stress can be determined easily be carried out. The possibility of such an experiment can be done with a pre-strained specimen ${ }^{(2)}$. This experimentation has been in progress, and the results will be published elsewhere ${ }^{(17)}$.

\section{On the Grain-Size Dependence of Transition Temperature}

In Fig. 9, the transition temperature is plotted as a

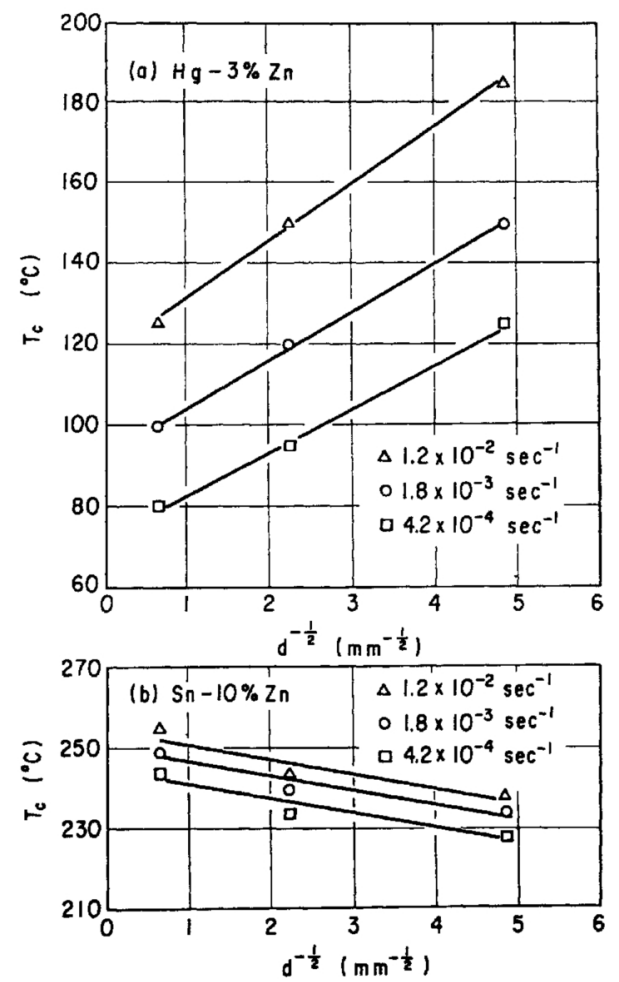

Fig. 9 Transition temperature as a function of grain size ; (a) in $\mathrm{Hg}-3 \% \mathrm{Zn}$ and (b) in $\mathrm{Sn}-10 \% \mathrm{Zn}$.

function of grain size, for three different strain rates. In $\mathrm{Hg}-3 \% \mathrm{Zn}$, the transition temperature is higher with decreasing grain size and the dependence is slightly larger with increasing strain rate. In $\mathrm{Sn}-10$ $\% \mathrm{Zn}$, the transition temperature is lower as the grain size becomes smaller and the dependence is almost the same for three strain rates.

(17) H. Ichinose and C. Oouchi : to be published. 


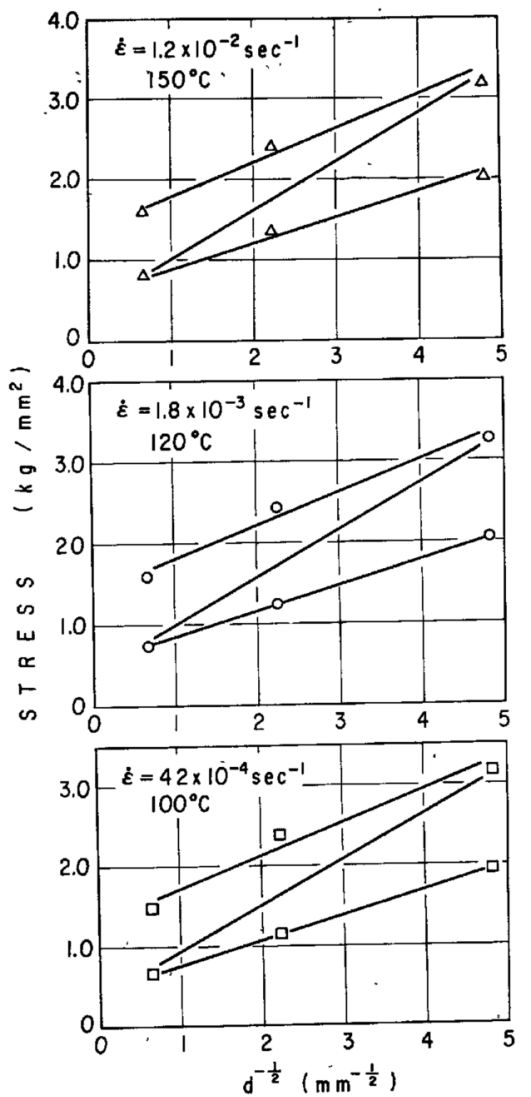

Fig. 10 Relation between the stress range (from the proportional limit to $5 \%$ flow stress)and grain size, with the expected value of $K_{p}$ (in $\mathrm{Hg}-3 \% \mathrm{Zn}$ ), at three strain rates.
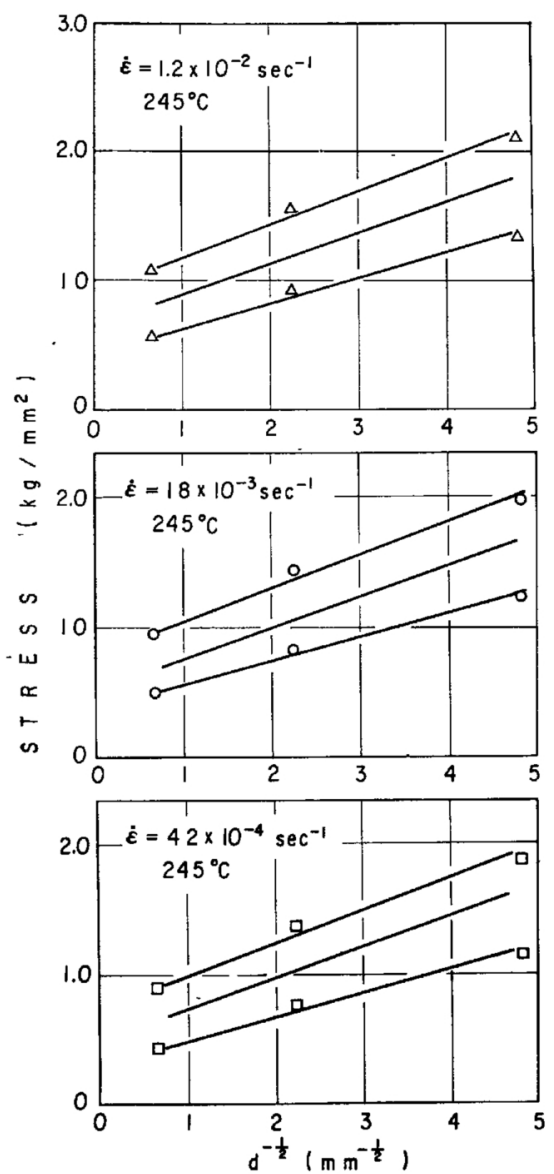

Fig. 11 Relation between the stress range (from the proportional limit to $5 \%$ flow stress) and grain size, with the expected value of $K_{p}(\mathrm{in} \mathrm{Sn}-10 \% \mathrm{Zn}$ ), at three strain rates.
The experimental results are analyzed in the same way as reported previously ${ }^{(2)}$. Fig. $10(\mathrm{Hg}-3 \% \mathrm{Zn})$ shows the relation between the stress range (from the proportional limit to $5 \%$. flow stress) and grain size at a prescribed temperature, the average of temperatures in which the transition took place at a particular strain rate. The value of $K_{p}$ is located at an arbitrary position in each case. It is much larger than that of $K y$, i.e., the grain-size dependence of yield stress.

Fig. 11 shows the results in $\mathrm{Sn}-10 \% \mathrm{Zn}$. The coincidence of $K_{p}$ and $K_{y}$ is observed because of the small temperature range in which the transition took place.

\section{Effect of Contact Time on Transition Temperature}

As the testing is done at a slower strain rate, a longer time is required for the contact between the liquid and solid metals. Simple dissolution of the solid metal into the liquid metal will not produce any effect on the ductility of the solid metal, unless the rate is very fast, and consequently the transition
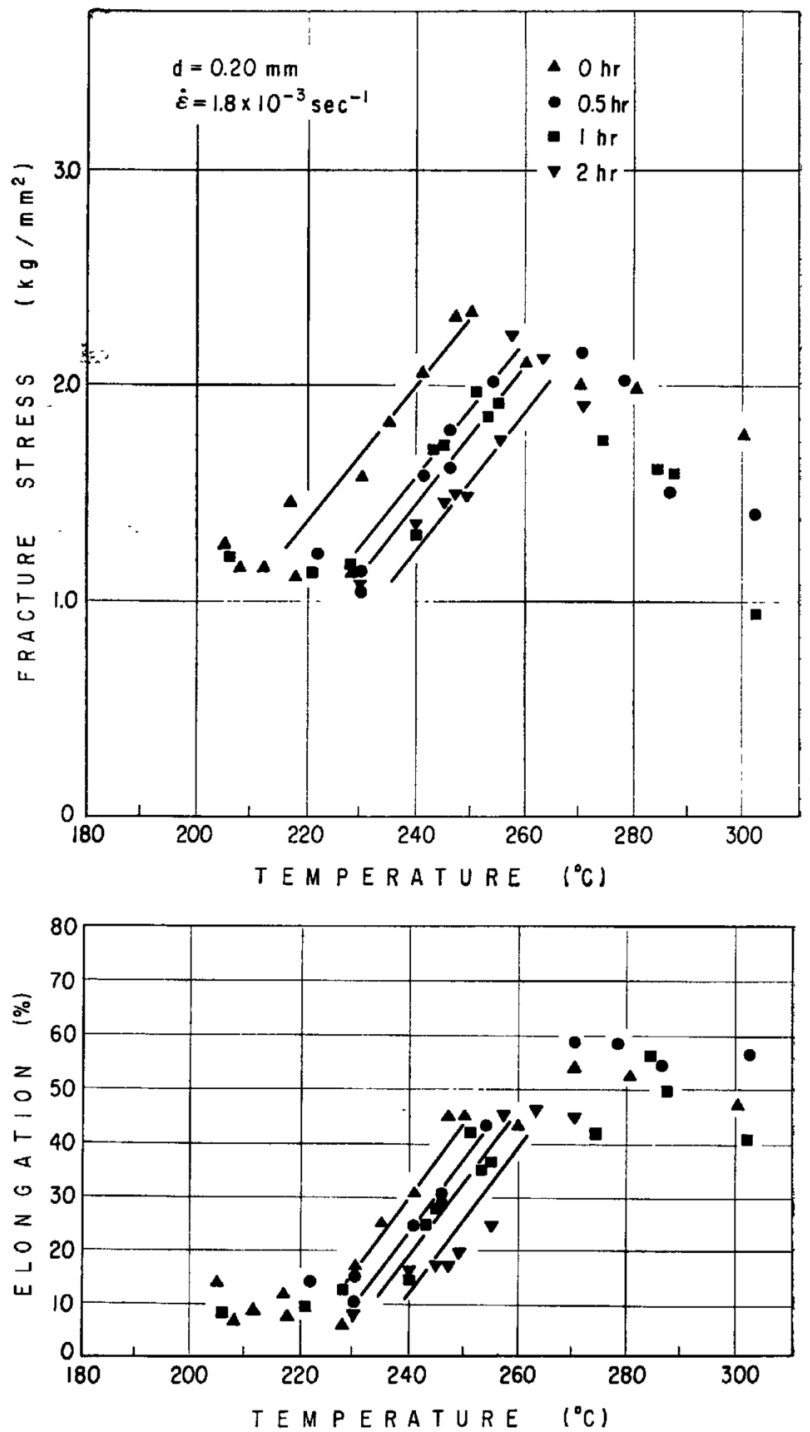

Fig. 12 Effect of the holding time on the transition temperature.

(18) H. Ichinose: Trans. JIM, 7 (1966), 56. 
temperature will not be changed. On the contrary, the grain-boundary diffusion of the embrittling liquid would change the transition temperature.

In $\mathrm{Hg}-3 \% \mathrm{Zn}$, the transition temperature is relatively low, and the grain-boundary diffusion during the testing can be neglected ${ }^{(18)}$. On the other hand, the ductile elongation is slightly affected in the presence of Sn-10\% $\mathrm{Zn}$ (Fig. 3). The contact time during the testing at the highest strain-rate was $10 \mathrm{~min}$, and that at the lowest was $25 \mathrm{~min}$ even at a temperature in the ductile region.

An experiment was performed on the specimen with a grain size of $0.20 \mathrm{~mm}$ in order to examine the effect of contact time on the transition temperature. After setting the specimen on the testing machine, the temperature was increased by a vertical electric furnace. At $198^{\circ} \mathrm{C}$ (m. p.), contact occurred and the temperature continued to increase until a desired temperature was reached. The specimen was kept at this temperature for $1 / 2,1$ or $2 \mathrm{hr}$, and then the testing was carried out at a strain-rate of $1.8 \times 10^{-3} \mathrm{sec}^{-1}$.
The results are shown in Fig. 12, in which the data on $0 \mathrm{hr}$ was obtained from Fig. 3 . Though the amount of change in transition temperature is not very large, it increases as the contact time increases. This may be due to the notch-sensitivity at the diffused grain boundary. As to the fracture stress, the points are scattered within the experimental error.

Thus, the value of $d T_{c} / d \log \dot{\varepsilon}$ in $\mathrm{Sn}-10 \% \mathrm{Zn}$ is slightly underestimated.

\section{Acknowledgments}

The authors would like to acknowledge their gratitude to Professor R.R. Hasiguti of University of Tokyo for the valuable advices given during the preparation of this manuscript.

The authors wish to express their thanks to Mr. T. Kuwahara and Mr. M. Shiga for the assistance in the experiment.

Thanks are also due to Mr. K. Hojio and Mr. H. Akità of the Central Research Institute, Furukawa Electric Co., for their kindness in preparing the specimens. 